\title{
ACESSO À EDUCAÇÃO SUPERIOR NO BRASIL: direito ou privilégio?
}

\author{
Silvia Maria Leite de Almeida \\ smalmeida@uneb.br \\ Universidade do Estado da Bahia - UNEB
}

\section{RESUMO:}

Este trabalho pretende mapear a concessão de condições de privilégios a determinado(s) grupo(s) para o acesso à educação superior no Brasil, através da sistematização da legislação educacional. Para tanto, foi realizado um exame do conteúdo das normas aprovadas que de certa forma concederam tal prerrogativa. Trabalhou-se a partir dos ordenamentos normativos presentes na história, seu limite são as Cartas Constitucionais de 1824 à 1988. Percebeu-se que muitos dos privilégios concedidos em relação ao acesso à educação superior foram regulamentados pelo Poder Legislativo. Enquanto esse Poder delegava ou se eximia de regular e regulamentar o acesso como um todo, não poupou esforços em conceder certas vantagens de ingresso para poucos. Dessa forma, enquanto o Executivo regulava e regulamentava as prerrogativas para acesso à educação superior, o Poder Legislativo regulava e regulamentava as formas "alternativas", ou melhor, privilegiadas, para grupos privilegiados. No início do século XX, o Legislativo foi o principal ator a manter a validade dos exames preparatórios, quando já havia uma discussão da fragilidade desse instrumento de avaliação. Um outro privilégio, fruto de uma lei originada e aprovada por esse Poder, nos anos de 1960, foi a "Lei do Boi", que concedia a reserva de vagas de até $50 \%$ nos estabelecimentos de ensino médio agrícola e escolas superiores de Agricultura e Veterinária mantidos pela União, para os candidatos agricultores ou aos seus filhos, proprietários ou não de terras. Correspondendo assim, de um tratamento preferencial, ou seja, destinado a um grupo privilegiado e não negativamente discriminado como uma política afirmativa supõe.

Palavras-chave: Acesso à educação superior no Brasil; privilégio; política de educação superior.

\section{ACESS TO SUPERIOR EDUCATION IN BRAZIL: right or privelege}

\begin{abstract}
:
This paper aim at mapping the concession of privileges to specifics groups in accessing superior education in Brazil through educational legislation. In this sense, we realized a content analysis of norms approved for this purpose. We studied laws through history from the constitutional acts of 1824 up to the one of 1988. We perceived that most privileges given in relation to access to superior education were ruled by the legislative. As this power did not care to rule in favor of universal access, it did not cut back efforts to concede vantage to some. This way, as the executive ruled about access to superior education, the legislative ruled about alternative access, or better, privileged access for special interest group. At the beginning of the twentieth century, the legislative was the main actor in the preservation of the preparatory exams while there was a discussion about their fragility. An other privilege given, was the consequence of a law approved by the legislative in the 1960, the "beef law", which gave a quota of $50 \%$ for farmers and their children in agriculture and veterinary school. This was a preferential treatment addressing the need of privileged group and not of a discriminated group as affirmative action implies.

Keywords: Access to superior education in Brazil; privilege; politics of access to superior education.
\end{abstract}




\section{Introdução}

Este trabalho pretende mapear a concessão de condições de privilégios a determinado(s) grupo(s) para o acesso à educação superior no Brasil, através da sistematização da legislação educacional, no período compreendido entre o Império e os anos de 1980. Para tanto, foi realizado um exame do conteúdo das normas aprovadas que de certa forma concederam tal prerrogativa.

Trabalhou-se a partir dos ordenamentos normativos presentes na história, seu limite se estabelece a partir das Cartas Constitucionais de 1824 à 1988. Percebeu-se que muitos dos privilégios concedidos em relação ao acesso à educação superior foram regulamentados pelo Poder Legislativo. Enquanto esse Poder delegava ou se eximia de regular e regulamentar o acesso como um todo, não poupou esforços em conceder certas vantagens de ingresso para poucos. Dessa forma, enquanto o Executivo brasileiro regulava e regulamentava as prerrogativas para acesso à educação superior, o Poder Legislativo regulava e regulamentava as formas "alternativas", ou melhor, privilegiadas, para grupos privilegiados. No início do século XX, o Legislativo foi o principal ator a manter a validade dos exames preparatórios, quando já havia uma discussão da fragilidade desse instrumento de avaliação.

Considero privilégio como "vantagem que se concede a alguém com exclusão de outrem e contra o direito comum" (FERREIRA, 1999). Ainda entendo que privilégio, sob uma hermenêutica jurídica, refere-se a "situação de superioridade, amparada ou não por lei ou costumes, decorrente da distribuição desigual do poder político e/ou econômico" (HOUAISS; VILLAR; FRANCO, 2001, p. 2301).

Para analisar a concessão de privilégios, o texto apresentará subdivisões que contemplará os diversos ordenamentos constitucionais da história brasileira.

\section{A CONCESSÃO DE PRIVILÉGIOS PRESENTE NO ORDENAMENTO A PARTIR DA CARTA DE 1824}

Um dos privilégios deste período que considero mais importante foi $\mathrm{o}$ regulamentado no Decreto 296-A, de 30/09/1843, o qual concedia aos diplomados no bacharelado em letras do Colégio Pedro II e dos estabelecimentos a ele equiparados o acesso direto aos cursos superiores do Império.

Devido à natureza do trabalho em questão, vou restringir a abordagem aos privilégios regulamentados em lei. Haidar (1972, p. 57) chama atenção que, durante um bom período, sobretudo na década de 60 do século XIX, muitas matrículas para os cursos superiores do Império foram realizadas através de leis individuais oriundas do Legislativo. Tal instância concedia aos requerentes que "não dispunham de todos os certificados de aprovação, matrícula condicional nas Faculdades". Desta forma, se concedia o ingresso à educação superior àqueles que não possuíam de forma integral todos os critérios para o acesso.

Este aspecto já tivera antecedentes quando a Lei de 11 de agosto de 1827 permitiu que, nos primeiros cinco anos, os alunos dos cursos jurídicos pudessem ingressar nos cursos sem prestarem o exame de aritmética e geometria. A eles estava concedida a possibilidade de realização de tais exames em qualquer época, desde que antecedesse a formatura. $\mathrm{O}$ 
próprio artigo que regulamentou esta permissão justificou tal ato: "E esta determinação, ou exceção da regra geral tem motivo em que atualmente se não acharão preparados os estudantes, que desejarem entrar neste Curso, e portanto passados os referidos cinco anos ninguém mais será admitido sem o mencionado exame, na forma do parágrafo antecedente" (BRASIL, 1827).

Um outro tipo de privilégio concedido chama a atenção e remete à questão da isenção de taxas. O Decreto 1.331-A, de 17/02/1854, aprovou o regulamento para a reforma do ensino primário e secundário do Município da Corte, admitindo que os alunos que se distinguissem na realização dos exames seriam premiados com a "isenção de direitos de matrícula no Colégio de Pedro II para tomar o grau Bacharel" ou com a mesma isenção nas academias de educação superior. Contudo, esta norma indicou que o Regulamento dependeria da "definitiva aprovação do Poder Legislativo" (BRASIL, 1854) e parece que não houve nenhum tipo de manifestação da Assembléia Legislativa, tanto que, em 10/05/1855, o Ministro Couto Ferraz publicou o Decreto n. 1.601, no qual mandava executar as instruções para os exames de que tratava o Regulamento da Instrução Primária e Secundária anexo ao Decreto 1.331-A, de 17/02/1854 (BRASIL, 1855). Esta norma concedia aos três primeiros candidatos que obtivessem aprovações com distinção nos exames para admissão aos cursos jurídicos a possibilidade de ingresso sem pagar as taxas de matrícula.

Essa prática foi retomada no Decreto 4.430, de 30/10/1869, sob forma um pouco diferenciada. Ao invés do candidato ter possibilidades de premiações, indicou que "o aluno aprovado com distinção em todas as matérias, não só receberá gratuitamente as certidões, mas também terá gratuitamente a matrícula do primeiro ano no estabelecimento público de instrução superior que pretender cursar" (BRASIL, 1869).

\section{A CONCESSÃo DE PRIVILÉgiOS PRESENTE NO ORDENAMENTO A PARTIR DA CARTA DE 1891}

Alguns dos privilégios verificados no período que compreende a promulgação da Carta Constitucional de 1891 à 1934 têm uma vinculação direta à realização dos exames preparatórios. Considero que a sua própria condição de prorrogação constitua uma espécie de privilegiamento.

Percebi que existiu um tratamento preferencial para os que possuíam o diploma de bacharel em letras. No Decreto 16.782-A, de 13/01/1925, conhecido como Reforma Rocha Vaz, que autorizou, independente da classificação, a entrada aos cursos superiores dos bacharéis, ou seja, aqueles que concluíram o sexto ano do ensino secundário. Seria importante chamar a atenção para este fato, pois, os bacharéis continuavam gozando privilégio, apesar da Lei orçamentária prever a extinção de qualquer tipo de vantagem para qualquer pessoa.

Essa condição tomou uma nova feição. Primeiro, o candidato não estava dispensado de realizar e ser aprovado no exame vestibular. Segundo, a partir dos anos de 1920, a quantidade de vagas oferecidas era inferior à quantidade de candidatos inscritos. O próprio fato de o candidato possuir o diploma já o colocava à frente dos demais, mesmo se no critério classificatório o candidato estivesse fora do estabelecido no numerus clausus; ou seja, havia uma reserva de vagas, mas não uma determinação de cotas, fato que não ocorria nos tempos imperiais. Lima e França (2002, p. 127) analisando este dispositivo, afirmam: 
O acesso democratizado ao nível superior podia ser questionado, através do parágrafo $3^{\circ}$ do artigo 27: "Entre os aprovados no exame [...], terão preferência para a matrícula, independente da ordem de classificação, os bacharéis em Ciências e Letras" [...], que representavam a própria caricatura do funil universitário. Não havia uma preocupação em construir a qualidade, mas em assegurar o status simbólico do capital cultural para alguns eleitos.

Assim como no período anterior, a gratuidade também acabou por se configurar num privilégio para alguns.

\section{A CONCESSÃO DE PRIVILÉgIOS PRESENTE NO ORDENAMENTO A PARTIR DA CARTA DE 1934}

Acredito que os privilégios mais importantes concedidos no ordenamento analisado foram praticamente da mesma natureza dos precedentes, ou seja, condições diferenciadas de acesso e condições de isenção de pagamento das taxas.

Quanto ao primeiro aspecto, percebi que a condição de estudante em colégios militares acabou sendo privilegiada como possibilidade de acesso aos cursos superiores. Foi o que inferi ao analisar a Lei 9-A, que anunciava:

Art. $9^{\circ}$. Os atuais alunos dos colégios militares que forem aprovados em $1934 \mathrm{em}$ todas as matérias de provas teóricas e práticas do $5^{\circ}$ ano do curso, inclusive o latim, pelo regulamento aprovado pelo decreto $\mathrm{n}^{\mathrm{o}} 18.729$, de 2 de maio de 1929 , poderão inscrever-se nos exames vestibulares de qualquer escola superior da República. (BRASIL, 1934)

Interessante perceber também nesta Lei um tratamento diferenciado, mesmo com estabelecimento de um tempo delimitado, para os estudantes dos cursos secundários noturnos. Pelo que pude perceber estes também gozariam do privilégio de não realizarem os cursos complementares para ingresso nos cursos superiores até o ano de 1936. Rezava o artigo sétimo da lei supracitada o seguinte:

Art. $7^{\mathbf{0}}$. O aluno maior de 18 anos [...] que já tenha concluído a $5^{\mathrm{a}}$ série ou venha a concluí-la até o período legal de 1936, inclusive, ficará isento do curso complementar, sujeito, entretanto, ao exame vestibular nas escolas superiores, a que se destina.

Parágrafo único - $\mathrm{O}$ aluno a que se refere a supra citada disposição prestará todos os exames nos estabelecimentos de ensino secundário, oficiais ou sujeitos a fiscalização da União. (BRASIL, 1934. Grifos meus)

Um fato curioso se esboça nessa Lei. Havia duas categorias, completamente diferentes dispensadas de realizar o curso complementar, até então obrigatório para ingressar em determinadas escolas superiores - os militares e os estudantes de cursos noturnos. Quanto ao primeiro grupo, não é de se estranhar tal privilegiamento, uma vez que este setor teve privilégios de outras instâncias no período em questão. Quanto ao segundo grupo, é interessante notar que para esse segmento historicamente discriminado, os estudantes dos cursos noturnos, abriu-se uma possibilidade de entrada nos cursos que exigiam mais dois anos de formação. É certo que essa facilitação pode ter ocasionado uma disputa em desigualdade de condições, no sentido de quem procurava as faculdades de alto prestígio deveria ter realizado uma formação especial destinada ao ingresso naquelas 
instituições que esses alunos não dispunham. Enquanto que, para os militares, não deveria haver uma diferença tão grande assim.

Um outro tipo de privilégio foi a possibilidade implementada pela Lei 23 , de $11 / 02 / 1935$, de alguns candidatos não realizarem o curso secundário formal, mas se beneficiarem da realização dos exames parcelados.

\section{A CONCESSÃO DE PRIVILÉGIOS PRESENTE NO ORDENAMENTO A PARTIR DA CARTA DE 1937}

Devido às condições de não equivalência dos ramos do ensino médio com o ensino secundário, que era o único ramo que permitia o ingresso para a seleção a todos os cursos da educação superior, os privilégios neste período foram essencialmente relacionados a essa questão, ou seja, da possibilidade que desfrutaram alguns grupos de possuírem uma condição especial de equivalência ao ensino secundário.

Dentre os privilégios relacionados a esse fato, destaco o Decreto-lei 5.550, de 4/06/1943, o qual permitiu aos estudantes que concluíssem o curso das Escolas Preparatórias a condição de equivalência ao "curso científico" inclusive para efeito de matrícula nas instituições de educação superior.

Sob essa isonomia de apresentação do certificado (ou prova) de conclusão dos cursos fundamental e complementar do ensino secundário ${ }^{1}$, o Decreto-lei 8.195, de 20/11/1945 ao alterar o artigo 31 do Decreto-lei 1.190, de 1939, incluiu um parágrafo que isentou alguns indivíduos que se enquadravam nas seguintes condições:

\footnotetext{
Art. 31. [...]

$\S 1^{\circ}$ A exigência da alínea a deste artigo poderá ser substituída, para inscrição no concurso de habilitação, pelo diploma, devidamente registrado, de qualquer curso superior reconhecido.

$\S 2^{\circ}$ Serão também dispensados, nos termos do parágrafo anterior e com as seguintes restrições:

a) os sacerdotes, religiosos e ministros de culto que tenham concluído regularmente os estudos em seminário idôneo, para os cursos de filosofia, letras clássicas, letras neo-latinas, letras anglogermánicas, e pedagogia;

b) os professores normalistas com o curso regular de pelo menos seis anos e exercício magisterial na disciplina escolhida, para os de pedagogia, letras neolatinas, letras anglo-germânicas, letras clássicas, geografia e história;

c) os professores já registrados no Departamento Nacional de Educação, com exercício eficiente por mais de três anos nas disciplinas do curso em que pretendam matricular-se;

d) os autores de trabalhos publicados em livro, considerados de excepcional valor pelo Conselho Técnico - Administrativo da Faculdade, no curso correspondente ao assunto científico, literário, filosófico ou pedagógico em apreço. (BRASIL, 1945)
}

Há aqui uma concessão muito clara aos clérigos e assemelhados de um privilégio, estendido a outras categorias, como os professores e escritores reconhecidos. Mas essa concessão não era de se estranhar uma vez que a própria Igreja Católica foi uma das grandes beneficiadas no Estado autoritário. 
Outra condição de privilégio foi a instalada com o Decreto-lei 3.143, de 25/03/1941, que permitiu, naquele mesmo ano, que candidatos que não tivessem atingido as notas necessárias à aprovação nos exames de habilitação repetissem o exame de uma ou duas disciplinas, nas quais tivessem tido média inferior a cinqüenta, ou seja, foi concedida mais uma chance a determinados alunos, talvez pelo não preenchimento da totalidade das vagas, fato comum à época, uma vez que o próprio ensino secundário já era bastante seletivo.

Uma outra concessão observada no período foi a propiciada pelo Decreto-lei 6.247, de 5/02/1944. Neste instrumento legal, o artigo primeiro indicou que, para o ano de 1944, as provas finais a que se referiu o Decreto-lei 21.241, de 1932 (Reforma do Ensino Secundário, de Francisco Campos), seriam "consideradas como um concurso de seleção para o preenchimento das vagas existentes na primeira série do estabelecimento de ensino superior em que os candidatos as realizarem" (BRASIL, 1944).

Ao que tudo indica, excepcionalmente, no ano de 1944, para a admissão aos cursos superiores que exigiam cursos complementares (Curso Jurídico, de Medicina, Farmácia, Odontologia, Engenharia e Arquitetura), foram aceitos os exames finais do último ano dos cursos complementares, prescindindo assim dos exames vestibulares. Não tenho elementos para avaliar se realmente esse decreto-lei foi colocado em execução, mas o fato de que quase vinte anos de instituído o exame vestibular, mesmo que essa condição de excepcionalidade se desse para alguns cursos e no prazo de somente um ano, o mesmo foi deixado de lado, sendo permitido o acesso aos cursos de forma direta. No entanto, para não ter sombra de dúvidas, trago, também, o artigo do Decreto-lei 6.247 que estabelece as disposições transitórias para a execução da Lei Orgânica do Ensino Secundário. Enuncia o seu artigo primeiro:

Art. $\mathbf{1}^{\mathbf{0}}$. No ano de 1944 , as provas finais a que especialmente se refere o art. 47 do Decreto-lei n. 21.241, de 4 de abril de 1932 serão consideradas como um concurso de seleção para preenchimento das vagas existentes na primeira série do estabelecimento de ensino superior em que os candidatos as realizarem. (BRASIL, 1944. Grifos meus)

Há no artigo segundo do Decreto-lei acima uma prática que vai se tornar constante no período subseqüente: os cursos de adaptação aos cursos clássico ou científico.

\section{A CONCESSÃo DE PRIVILÉgIOS PRESENTE NO ORDENAMENTO A PARTIR DA CARTA DE 1946}

Nesse período os privilégios foram relativos à equivalência do ensino médio para alguns setores ${ }^{2}$ e à gratuidade. Velhos privilégios acabaram ressurgindo, como a questão dos prazos para a realização dos concursos e a possibilidade de realizar uma segunda chamada, mas não houve, praticamente, nenhuma novidade.

Quanto à equivalência do ensino secundário, o que pude perceber durante este período foi a publicação de uma série de normas que acabaram por conceder essa para alguns cursos de nível médio (antes só era reconhecido quem concluía o ramo clássico ou científico). A Reforma de 1942, que estabeleceu a Lei Orgânica do Ensino Secundário, acabou por reproduzir a não equivalência dos cursos profissionalizantes/técnicos em relação ao curso secundário, diga-se, aos cursos clássico ou científico. Somente aos alunos que tivessem concluído aqueles cursos seria concedida a possibilidade de inscrição para qualquer curso superior. Aos que não tivessem feito tais cursos só seria possível realizar a 
inscrição para os concursos de habilitação aos quais os seus cursos estivessem "subordinados" - e após fazer uma espécie de "adaptação".

A exemplo do que já tinha acontecido no ano de 1945, através do Decreto-lei 8.195, que estabeleceu condição especial para pessoas que se enquadravam em condições de sacerdócio, professores e autores de livros, outra norma reforçou aquela condição estabelecida através do Decreto-lei 8.195. Esta norma, uma Portaria da Diretoria de Educação Superior, órgão vinculado e subordinado ao Ministério da Educação, reeditou as condições de excepcionalidade bem como os critérios para que fossem aceitas tais condições.

Percebe-se na norma preocupação com alguns requisitos, como a validade dos cursos, a duração, as comprovações necessárias, além de, no caso dos autores, um "minucioso" parecer do Conselho Técnico e Administrativo da instituição de educação superior na qual o candidato pretendia ingressar.

Uma condição de privilégio foi esboçada para mais uma categoria: os jornalistas. Em março de 1949, foi publicado o Decreto 26.493, oriundo do Poder Executivo, de reorganização do curso de Jornalismo. Para o ingresso nos anos de 1949 e 1950, os jornalistas inscritos na associação de classe ou que tivessem a carteira expedida pelo Ministério do Trabalho, poderiam ingressar no primeiro ano do curso, só apresentando uma "prova de sanidade". Reproduzo o artigo para melhor compreensão:

Art $3^{\circ}$. O candidato à matrícula como aluno regular na primeira série da Seção de Formação $^{3}$, deverá:

a) apresentar certificado de curso secundário do $2^{\circ}$ ciclo;

b) apresentar prova de identidade;

c) apresentar prova de sanidade;

d) apresentar prova de idoneidade moral;

e) prestar exame vestibular.

Parágrafo único. Aos candidatos à matrícula na primeira série, nos anos letivos de 1949 e 1950, que sejam jornalistas inscritos na associação de classe ou apresentem carteira profissional expedida pelo Ministério do Trabalho, Indústria e Comércio, será dispensadas, as exigência desse artigo, com a exceção da prevista nas alíneas c. (BRASIL, 1949. Grifos meus)

Entendo que esse dispositivo constitui-se como um privilégio. É de conhecimento que a categoria dos jornalistas historicamente vem travando uma luta sobre a regulamentação da profissão. A inclusão desse dispositivo viria a facilitar aos jornalistas de fato, a tornarem-se de direito.

Houve ainda privilégios referentes à concessão de uma segunda época para realização dos exames e de períodos especiais para a prestação de provas. Quanto à realização de um segundo concurso vestibular, foi devido ao não preenchimento das vagas no primeiro concurso, pelo critério habilitatório, ou seja, o alcance da nota mínima. Aliás, esse privilégio foi regulamentado por uma norma que fazia parte do ordenamento normativo da Carta Constitucional de 1937, ainda não revogado. Refiro-me ao Decreto-lei 9.154, de 8/04/1946, que autorizava a realização de um segundo concurso de habilitação nos estabelecimentos de educação superior.

O critério habilitatório, ou seja, o alcance de uma nota mínima, durante um bom tempo, foi empecilho para o preenchimento da totalidade das vagas oferecidas pelas instituições de educação superior. Era comum para alguns cursos o não preenchimento de todas as vagas na realização do primeiro vestibular, pois, poucos candidatos conseguiam alcançar a nota de habilitação. Após a publicação do Parecer do Conselho Federal de 
Educação (CFE) 58/62 houve uma interpretação equivocada de permitir, por parte de algumas instituições, que as vagas fossem ocupadas tão somente pelo critério classificatório, não levando em conta o critério habilitatório (nota mínima). O Parecer 166/64 veio corrigir esta distorção conjugando numerus clausus com nota mínima. Mesmo assim, algumas instituições ainda realizavam uma série de concursos vestibulares, para preencher suas vagas, pois era comum que no primeiro concurso vestibular não houvesse candidatos suficientes, dentre os que alcançavam o critério de habilitação. Às vezes, eram feitas mais de três tentativas, pois não dava para lançar mão das hoje famosas "listas de espera".

\section{A CONCESSÃO DE PRIVILÉGIOS PRESENTE NO ORDENAMENTO A PARTIR DA CARTA DE 1967}

O período que compreende a outorga da Constituição de 1967 à véspera da promulgação da Constituição de 1988, houve dois tipos de privilégios: os concedidos e os reclamados. Os concedidos foram publicizados através da legislação positivada. Já os reclamados foram objeto de reivindicações jurídicas, que nem sempre foram atendidas.

O primeiro privilégio, que pude perceber a partir da Carta de 1967, foi publicizado em norma editada no ano de 1968, pelo Poder Legislativo. Tratou-se da Lei 5.465, de 3/07/1968, conhecida vulgarmente como a "Lei do Boi". Nela, originariamente, foi concedida a possibilidade de uma reserva de vagas de até $50 \%$ nos estabelecimentos de ensino médio agrícola e escolas superiores de Agricultura e Veterinária mantidos pela União, para os candidatos agricultores ou aos seus filhos, proprietários ou não de terras. A "Lei do Boi" inaugurou na educação superior brasileira a política de cotas.

Gomes (2003) faz alusão à "Lei do Boi” como uma ação afirmativa "bem brasileira", porém não a considero desta forma, mas como um tratamento preferencial, ou seja, destinado a um grupo privilegiado e não negativamente discriminado como uma política afirmativa suporia.

A título de uma maior visibilidade, transcreverei uma boa parte da "Lei do Boi" para análise:

\footnotetext{
Art $1^{\circ}$ Os estabelecimentos de ensino médio agrícola e as escolas superiores de Agricultura e Veterinária, mantidos pela União, reservarão, anualmente, de preferência, de 50\% (cinqüenta por cento) de suas vagas a candidatos agricultores ou filhos destes, proprietários ou não de terras, que residam com suas famílias na zona rural e $30 \%$ (trinta por cento) a agricultores ou filhos destes, proprietários ou não de terras, que residam em cidades ou vilas que não possuam estabelecimentos de ensino médio.

$\S 1^{\circ}$ A preferência de que trata este artigo se estenderá os portadores de certificado de conclusão do $2^{\circ}$ ciclo dos estabelecimentos de ensino agrícola, candidatos à matrícula nas escolas superiores de Agricultura e Veterinária, mantidas pela União.

$\S 2^{\circ}$ Em qualquer caso, os candidatos atenderão às exigências da legislação vigente, inclusive as relativas aos exames de admissão ou habilitação. (BRASIL, 1968a)
}

Dentre os motivos que incentivaram a criação desta lei, estavam justamente um movimento contrário ao dos excedentes e uma influência da Agência Americana para o Desenvolvimento Internacional - USAID ${ }^{4}$. Um dos grandes problemas da década de 1960 foi a crescente questão dos excedentes, os candidatos aprovados, porém não classificados. 
No entanto, este não era um problema generalizado, havia muitos candidatos aprovados nos concursos vestibulares para cursos como Medicina e Engenharia, mas para outros cursos essa relação era inversa, ou seja, havia cursos nos quais a quantidade de vagas era maior do que a de candidatos aprovados e/ou até mesmo inscritos para os respectivos concursos vestibulares. Os cursos dos estabelecimentos de ensino agrícola se destacavam justamente por essa carência de candidatos.

\begin{abstract}
Para articular a pretensão dessas escolas, de aumentar o número de estudantes, com a política governamental (e da USAID) de aumentar a produção de alimentos e, ainda, com a difusa procura por ensino médio e superior da parte dos jovens oriundos da zona rural, surgiu uma das mais curiosas medidas de política educacional, que veio a ser conhecida como "lei do boi". (CUNHA,1988, p. 90)
\end{abstract}

Esta lei foi objeto de crítica em 1984, por parte de Carlos Alberto Serpa de Oliveira, quando participou de um seminário promovido pela Fundação Carlos Chagas. Foi membro do Comissão Nacional do Vestibular Unificado - CONVESU e relatou a postura de perplexidade daquele órgão ao se deparar com a "Lei do Boi". Oliveira, à época do seminário realizado em 1984, informou que aquela lei ainda vigia, que a mesma era "uma lei de privilégio, uma lei inconstitucional", mas não indicou a pecha constitucional. Mencionou que o CONVESU, inclusive, "levou o problema ao Procurador Geral da República, para que ele dissesse que a lei era inconstitucional e não podia ser aplicada, até porque não havia um decreto que a regulamentasse" (OLIVEIRA, 1985, p. 17). No entanto, como o autor não indicou quando foi realizada essa consulta, creio que, equivocou-se aquele grupo, ou a lei foi regulamentada logo após a consulta do CONVESU, pois, a "Lei do Boi" acabou por ser adjetivada pelo Decreto 63.788, de 1968.

Neste Decreto algumas questões foram esclarecidas como o percentual de reserva. $\mathrm{Na}$ regulamentação ficou claro que o índice era de $50 \%$ das vagas das escolas de Agricultura e Veterinária, que estavam reservadas "preferencialmente" para candidatos agricultores ou filhos destes, proprietários ou não de terras, que residam com suas famílias na zona rural e não 80\% das vagas como podia ser inferido na Lei (BRASIL, 1968b).

Quanto à questão da residência dos candidatos, ou seja, para que o pretendente pudesse ser privilegiado com aquela política de cota, era necessário que o mesmo morasse em zona rural. $\mathrm{O}$ autor denunciou que essa condição, no Estado do Rio de Janeiro, era desaforadamente burlada e desabafou:

\footnotetext{
Essa lei passou a funcionar neste país e até hoje [1984] ninguém conseguiu derrubá-la. Na aplicação da lei, o certificado que dá esta benesse é fornecido pelo INCRA. No caso do Rio de Janeiro, quem tem uma casa em Petrópolis, Teresópolis, qualquer casa de campo, qualquer casa que saia do perímetro urbano recebe o certificado do INCRA, de maneira que passou a ser praticamente um privilégio de todos, menos daqueles que, certamente por falta de poder aquisitivo, não têm uma casa no campo. Mais uma vez foi uma lei que veio a prejudicar pessoas de menor poder aquisitivo. (OLIVEIRA,1985, p. 15-16)
}

A "Lei do Boi" só foi totalmente revogada 17 anos após a sua publicação, através da Lei 7.423, de 17/12/1985, do Congresso Nacional. Creio que houve uma resistência em extinguir tal ato pelo próprio fato do mesmo ter acabado privilegiando uma parcela da camada média que buscava no "Brasil rural" a sua ascensão.

No entanto, outros tipos de tratamentos preferenciais foram destinados a grupos seletos. Refiro-me aos estudantes estrangeiros dependentes dos representantes diplomáticos e consulares. Para esse grupo de jovens, duas normas foram específicas em garantir vagas 
independentes de sua existência e da realização de concurso vestibular para ocupá-las, além de promover a isenção da taxa de matrícula.

Essas normas foram publicadas uma na década de 1970 - o Decreto 71.835 , de 13/02/1973 (BRASIL, 1973a) - e, outra na década de 1980 - o Decreto 89.758, de 6/06/1984 (BRASIL, 1984b). Enquanto o primeiro decreto previu matrícula em universidades, o segundo ampliava o rol para "Instituições de Ensino Superior". No entanto, essa condição não isentava o suposto aluno de arcar com as outras despesas do curso (mensalidades, entre outras taxas). Não sei até que ponto essa medida poderia ser comparada a um tipo de transferência, mas há de se considerar que, nas duas normas citadas acima, houve uma concessão especial, principalmente a isenção da taxa de matrícula.

Um outro privilégio, também ao arrepio da CONVESU, foi a indicação de adicionar um critério de aumento das notas de candidatos oriundos do ensino profissionalizante. Refiro-me ao Decreto 73.079, de 5/11/1973 (BRASIL, 1973b), burilado pelo Decreto 75.369, de 13/02/1975, que permitiu aos estabelecimentos de educação superior vinculados ao sistema federal de ensino (ou seja, estabelecimentos federais e privados), a partir do ano de 1976, o acréscimo de 3\% a $10 \%$ da pontuação obtida pelos candidatos no concurso vestibular que tivessem concluído curso profissionalizante de $2^{\circ}$ grau, como pode ser visto no trecho que segue:

\begin{abstract}
Art. $\mathbf{1}^{\mathbf{0}}$. A partir de 1976 os estabelecimentos de ensino superior vinculados ao sistema federal de ensino deverão acrescer de $10 \%$ e $3 \%$, respectivamente, o total de pontos obtidos pelos concorrentes nos exames vestibulares que tiverem apresentado, na inscrição, certificado comprobatório de término de curso profissionalizante de $2^{\circ}$ grau, com mais de 1.100 horas de formação especial, ou de curso de auxiliar-técnico, com 300 horas de formação especial.

Parágrafo único. O Ministério da Educação e Cultura estabelecerá as condições e a oportunidade para cumprimento do disposto neste artigo. (BRASIL, 1975)
\end{abstract}

Esta medida acabou por não se efetivar. Informa Oliveira (1985) que esse Decreto foi uma solicitação direta do Presidente do Conselho Federal de Educação ao Ministro da Educação, sem antes haver consultado o CONVESU. Esse decreto entrava em franca contradição com a Lei 5.692/71 que pretendia, entre outros objetivos, uma profissionalização a nível médio dos estudantes para conter a grande procura de candidatos pela educação superior. Nas palavras de Oliveira (1985, p. 17), esse decreto acabou por "estimular as pessoas que terminavam esses cursos de profissionalização intermediária a irem ao vestibular em igualdade de condições com os outros, igualdade esta que era superada pela apresentação de um simples diploma de curso profissionalizante". Mal entendidos à parte, Oliveira continua relatando que devido à grande proximidade do Ministro com aquela Comissão, foi realizado um "milagre", pois,

O Palácio do Planalto, no dia seguinte ao que descobrimos a ocorrência do fato, anunciou que havia publicado errada a vigência do decreto, que em lugar de entrar em vigência no ato da sua assinatura, somente valeria dali a três anos. Foi uma medida política do Ministro Jarbas Passarinho. Posteriormente, o decreto foi revogado sem ser aplicado. (OLIVEIRA, 1985, p. 17)

Esse decreto foi revogado alguns anos depois, através do Decreto 89.311, de 23/01/1984, ao que parece, sem nunca ter privilegiado nenhum postulante (BRASIL, 1984a).

Até então só me referi aos privilégios concedidos; houve também as vantagens reclamadas que, a depender, foram atendidas ou negadas. Essas solicitações foram objeto de 
reivindicações jurídicas que desembocaram no Conselho Federal de Educação resultando em pareceres e algumas resoluções.

O Parecer 970, de 1969, dispensou do concurso vestibular para a Faculdade de Filosofia, Ciências e Letras ou para a Faculdade de Educação, os candidatos portadores de diplomas de Cambridge, Michigan, Nancy ou Madrid. Segundo o relator do Parecer, Luciano Duarte, afirmava que parecia

\begin{abstract}
[...] não ter sentido que um aluno que já cursou as disciplinas pedagógicas num curso superior, e nelas obteve aprovação, seja obrigado, quando quiser cursar as restantes disciplinas para a obtenção regular da licenciatura, a submeter-se ao concurso vestibular. Os objetivos visados pelo concurso vestibular, tais como aparecem no art. 21 da Lei 5.540 [...] já foram atingidos, implicitamente, pelo fato da aprovação nas disciplinas pedagógicas.

Nem se alegue que isto seria abrir um atalho pelo qual os candidatos iludiriam o obstáculo do concurso vestibular. Na realidade, a obtenção de um diploma de Cambridge parece-nos ao menos tão difícil quanto a aprovação num vestibular. (BRASIL, 1969)
\end{abstract}

Dois pareceres do CFE me chamaram a atenção quanto à questão de uma negação de privilégios. O primeiro opinou sobre a questão da "má fé" e outro da questão dos "supostos superdotados". No entanto, em ambos os casos havia uma condição em comum: a aceitação da matrícula, após aprovação no concurso vestibular, porém sem a conclusão do $2^{\circ}$ grau.

O Parecer 881/70, do CFE, estabeleceu normas sobre alunos que ingressaram em curso de nível superior com a apresentação de documentos falsos, referentes à prova de conclusão do curso de nível médio. Segundo o relator havia uma rica "jurisprudência [do] Egrégio Conselho no sentido de que as irregularidades ocorridas em curso de ensino médio não atingem posteriormente os realizados, embora não fiquem os culpados eximidos das penalidades criminais cabíveis" (BRASIL, 1970), ou seja, o CFE emitiu vários pareceres resultantes de consultas sobre situações de alunos que logravam aprovação no concurso vestibular, se matriculavam, cursavam parte dos estudos superiores, no entanto não havia concluído o ensino médio, pré-requisito, estabelecido na legislação educacional desde 1925, para ingresso aos cursos superiores.

Para estes casos, o CFE foi condescendente no sentido de permitir, depois de sanada a irregularidade, prosseguir seus estudos do ponto onde havia interrompido. No entanto, chamava a atenção às instituições que foram "relapsas" na verificação dos pré-requisitos, correndo o risco de que, se tais fatos continuassem ocorrendo, perdessem as suas credenciais de instituições de educação superior. Sobrino Pôrto (1970, p. 24) chamava a atenção para tal fato, dizia ele:

\footnotetext{
Ocorre, entretanto, e com maior freqüência do que seria de desejar, que instituições de nível superior têm admitido à prestação do concurso vestibular e, inclusive, à matrícula na primeira série, a estudantes que não completaram o ciclo colegial, sob o pressuposto, ao que parece, de que o complementarão a seguir.
}

O Parecer 881/70 alertava para um fato considerado bastante grave. Ao que parece, uma quantidade considerável de estudantes ${ }^{5}$ da Faculdade de Direito de Bragança Paulista teve suas matrículas canceladas em conseqüência de irregularidades na documentação apresentada quando se submeteram ao concurso vestibular; os alunos haviam apresentado certificados de conclusão do ensino médio falsos.

Informava aquele Parecer que a Chefe do SFVE (?) ${ }^{6}$ do Departamento de Assuntos Universitários, Elza Gomide, atentava para o fato de não ter havido, até aquele momento, 
nenhuma punição pela utilização de documentos falsos para a matrícula em escolas superiores. "Assim, o estudante nada tem a perder. Se não for descoberta a fraude, tanto melhor, se for - não há problemas: recorre-se ao Exame de Madureza e o assunto fica liquidado" (CONSELHO FEDERAL DE EDUCAÇÃO, 1970).

O Parecer colocou duas situações diversas: a ausência da má-fé pela apresentação de documentos insuficientes, como exemplifica a seguinte situação: o candidato se inscreve para o vestibular que ocorrerá em janeiro, mas só vai obter "a prova de conclusão do curso de nível médio no mês seguinte" (CONSELHO FEDERAL DE EDUCAÇÃO, 1970). E a segunda situação foi justamente quanto havia a má-fé, ou seja, a apresentação de documentos falsos ou outros fatos considerados criminosos. Argumentou o Parecer:

\begin{abstract}
Impõe-se, pois, que se distingam as duas atuações: - no $1^{\circ}$ caso, isto é, comprovada ausência de dolus malus, ou má-fé basta a regularização do curso secundário para que o aluno prossiga no curso superior interrompido; no segundo caso porém, impõe-se a aplicação de alguma sanção, que sugerimos consista em ficar o aluno impedido de prosseguir o curso superior durante dois anos, a contar do dia em que regularizou o seu curso de nível médio. O instrumento adequado poderia ser uma resolução deste Egrégio Conselho, que viria dar à aludida jurisprudência maior força. Porque não mais serviria de escudo aos que se utilizassem de fraude, má-fé, ou dolus malus. (CONSELHO FEDERAL DE EDUCAÇÃO, 1970) Grifos originais)
\end{abstract}

O outro caso referiu-se aos alunos que se consideravam "superdotados". Essa situação foi devido ao fato do CFE ter recebido vários pedidos de concessão de matrículas a candidatos que foram aprovados no concurso vestibular, mas só tinham cursado o $2^{\circ}$ ano do $2^{\circ}$ grau, (até mesmo o primeiro ano). Estes alunos, para pleitear a concessão da matrícula no estabelecimento de educação superior, sem o cumprimento do seu pré-requisito, julgavamse "superdotados", motivo suficiente para que o CFE permitisse tal condição especial, sem a conclusão do ensino médio.

O Parecer 436, aprovado em 8/05/1972, jogou uma "pá de cal” na questão. Segundo Abgar Renault, seu relator,

\begin{abstract}
O mecanismo quase sempre é o mesmo. Ainda no ensino de $2^{\circ}$ grau, e não raro logo no início, o aluno tenta o Concurso Vestibular com o propósito de familiarizar-se com o seu estilo, com o seu conteúdo e até com o seu ambiente. Nada tem a perder, e muito poderá lucrar. Se não obtém classificação, sempre alcançará o objetivo inicial de "aprender vestibular"; e se a obtém, este resultado não imediatamente colimado lhe chega como autêntica sorte-grande a elevar-lhe o nível de aspiração. (CONSELHO FEDERAL DE EDUCAÇÃO, 1972)
\end{abstract}

Segundo o relator, o caminho utilizado por tais alunos foi explorar o princípio pedagógico "de que ao superdotado cabe dispensar um tratamento especial que, no caso, importaria na validação do vestibular realizado prematura e indevidamente" (CONSELHO FEDERAL DE EDUCAÇÃO, 1972), pois apesar de terem cumprido satisfatoriamente a alínea "b" do art. 17, da Lei 5.540, ou seja, a classificação no concurso vestibular, não atendiam a alínea "a" que condiciona a segunda, ou seja, a conclusão do ensino de $2^{\circ}$ grau.

Após indicar a própria dinâmica dos "cursinhos" pré-vestibulares como um dos causadores do problema e também da própria execução do vestibular que não aprovava e não reprovava, simplesmente classificava, Renault fez uma afirmação que considero um primor:

Se ao menos os aspirantes a excepcionais lograssem classificações também excepcionais, situando-se entre os cinco ou dez primeiros, ainda haveria um certo 
elemento de dúvida. A verdade, porém, é que isso não tem ocorrido; e alcançar um número inexpressivo de pontos, no sistema de provas que se adota, é algo que pode ser conseguido até por acaso. (CONSELHO FEDERAL DE EDUCAÇÃO, 1972)

O Parecer final admite a inscrição condicional de estudante superdotado, à vista de parecer do Conselho "em que se reconheça a sua excepcionalidade positiva" (CONSELHO FEDERAL DE EDUCAÇÃ̃, 1972). No entanto, mesmo aceitando essa condição, o aluno deveria apresentar dentro de um período estipulado, os certificados de escolarização completa de $1^{\circ}$ e $2^{\circ}$ graus, caso contrário, não receberiam o diploma do curso superior.

Este caso relatado no Parecer 436/72 refletiu bem um problema que permaneceu durante um bom tempo na trajetória do concurso vestibular, os denominados "treineiros" que, como bem relatou Renault, realizavam o concurso vestibular antecipadamente para "treinar" e acabavam causando um grande transtorno às instituições de educação superior, por reclamarem um suposto direito. Hoje esse problema já foi contornado pelas próprias instituições de educação superior que prevêm a existência desse público e deixam explícito nos seus editais que em hipótese nenhuma será concedida a matrícula ao candidato aprovado e classificado no concurso vestibular, sem ter concluído o ensino médio.

\section{A CONCESSÃo DE PRIVILÉgIOS PRESENTE NO ORDENAMENTO A PARTIR DA CARTA DE 1988}

A partir do novo ordenamento normativo marcado pela Carta Constitucional de 1988 e também de um maior movimento de procura pela educação superior não percebi, pelo ao menos na legislação pertinente, nenhum dispositivo que concedesse algum tipo de privilégio para acesso à educação superior. No entanto, alguns poderão vir a discordar desta observação e afirmar que existe sim um processo de privilégio de acesso à educação superior estabelecido por algumas instituições, sobretudo universitárias, de reserva de vagas.

Gostaria de deixar claro que, na minha concepção, a reserva de vagas é algo que não encaro e nem enquadro como privilégio, pois, por fazer parte das chamadas políticas de ação afirmativa, vem no sentido de, justamente, promover setores menos favorecidos da sociedade brasileira, visando dirimir os efeitos que se revelam "na chamada discriminação estrutural, espelhada nas abismais desigualdades sociais entre grupos dominantes e grupos marginalizados" (GOMES, 2003, p.30, grifos originais).

Apesar de não perceber no período nenhum tratamento especial concedido sob a forma de privilégio, isso não quer dizer que o mesmo não fosse reclamado. Assim o fez o Instituto Educacional Evangélico Brasileiro, do Distrito Federal, quando consultou o Conselho Nacional de Educação - CNE sobre a possibilidade de manter o privilégio alcançado no período da Ditadura Militar, pelo qual, alguns setores, e os clérigos aí estavam incluídos, eram dispensados de realizar concurso vestibular para ingresso em determinados cursos. O privilégio adquirido no período político anterior, foi regulamentado através do Decreto-lei 1.051, de 1969, que facultava aos portadores de diplomas adquiridos nos 
Seminários Maiores, Faculdades Teológicas e instituições congêneres o ingresso em cursos de licenciatura sem realizar concurso vestibular.

Dessa forma ficou evidenciado que, com a publicação da Lei de Diretrizes e Bases de 1996 (Lei 9.394), os possíveis tipos de privilegiamento não seriam acatados por nenhuma instância regulamentadora do sistema oficial de educação superior, fosse o MEC ou o CNE. Exceção são os privilégios concedidos aos funcionários e seus dependentes de consulados ou embaixadas internacionais continuavam sendo facultados, pois os dispositivos legais, não foram revogados.

\section{8 À GUISA DE CONCLUSÃo}

Interessante perceber que muitos dos privilégios concedidos em relação ao acesso à educação superior foram regulamentados pelo Poder Legislativo. Enquanto esse Poder delegava ou se eximia de regular e regulamentar o processo como um todo, não poupou esforços em conceder certas vantagens para poucos. Dessa forma, enquanto ainda vigoravam os exames preparatórios, foi o Poder Legislativo que concedeu, através de inúmeras normas, a possibilidade de determinados candidatos se matricularem nos cursos de educação superior sem terem todos os exames exigidos.

O Poder Legislativo foi o principal ator a manter a validade dos exames preparatórios, quando já havia uma discussão da fragilidade desse instrumento de avaliação e da premente necessidade de que o candidato finalizasse seus estudos secundários, sem recorrer ao artifício dos exames parcelados. Um outro privilégio, fruto de uma lei originada e aprovada por esse Poder, foi a "Lei do Boi".

A partir do ordenamento normativo da Carta de 1988 não percebi nenhum movimento de concessão de privilégio, apesar deste tratamento especial continuar sendo reclamado. No entanto, estas solicitações não repercutiram em nenhuma medida normativa. 


\section{REFERÊNCIAS}

BRASIL (1827). Lei s/n., de 11/08/1827. Coleção das Leis do Império do Brasil. V. 1, p. $5-39,1827$.

BRASIL (1843). Decreto 296-A, de 30/09/1843. Coleção das Leis do Império do Brasil. V. 1, p. 33.

BRASIL (1854) Decreto 1.331-A, de 17/02/1854. Coleção das Leis do Império do Brasil. Tomo 17, Parte 2, Seção 12, p. 45-69.

BRASIL (1855). Decreto 1.601, de 10/05/1855. Coleção das Leis do Império do Brasil. V. 1, p. 396-399.

BRASIL (1869). Decreto 4.430, de 30/10/1869. Coleção das Leis do Império do Brasil. V. 1, p. 418-425.

BRASIL (1925). Decreto 16.782 A, de 13/01/1925. Coleção de Leis do Brasil. V. 1, p. 2095.

BRASIL (1934). Lei 9-A, de 12/12/ 1934. REITORIA DA UNIVERSIDADE DE SÃO PAULO. Legislação Federal do Ensino Superior: 1825/1952. São Paulo, 1953, p. 191193.

BRASIL (1935). Lei 23, de 11/02/1935. Disponível em: <http://www.senado.gov.br> Acesso em: 26 jun. 2003.

BRASIL (1939). Decreto-Lei 1190, de 04/04/1939. Disponível em: <http://www.senado.gov.br> Acesso em: 14 jul. 2003.

BRASIL (1941). Decreto-Lei 3.143, de 25/03/1941. Disponível em: $<$ http://www.senado.gov.br> Acesso em: 14 jul. 2003.

BRASIL (1943). Decreto-Lei 5.550, de 04/06/1943. Disponível em: $<$ http://www.senado.gov.br> Acesso em: 14 jul. 2003.

BRASIL (1944). Decreto-Lei 6.247, de 05/02/1944. Disponível em: $<$ http://www.senado.gov.br> Acesso em: 14 jul. 2003.

BRASIL (1945). Decreto-lei 8.195, de 20/11/1945. Disponível em: <http://www.senado.gov.br> Acesso em: 14 jul. 2003.

BRASIL (1946). Decreto-Lei 9.154, de 08/04/1946. Disponível em: <http://www.senado.gov.br> Acesso em: 14 jul. 2003.

BRASIL (1949). Decreto 26.493, de 19/03/1949. Disponível em: <http://www.senado.gov.br> Acesso em: 30 jul. 2003.

BRASIL (1968a). Lei 5.465, de 03/07/1968. In: SENADO FEDERAL (2002). Secretaria de Informação e documentação. Subsecretaria de Informações. Legislação Republicana Brasileira. Brasília, 1 CD-ROM.

BRASIL (1968b). Decreto n. 63.788, de 12/12/1968. In: SENADO FEDERAL (2002). Secretaria de Informação e documentação. Subsecretaria de Informações. Legislação Republicana Brasileira. Brasília. 1 CD-ROM. 
BRASIL (1969). Decreto-lei 1.051, de 21/10/1969. In: SENADO FEDERAL (2002). Secretaria de Informação e documentação. Subsecretaria de Informações. Legislação Republicana Brasileira. Brasília. 1 CD-ROM.

BRASIL (1973a). Decreto 71.835, de 13/02/1973. In: SENADO FEDERAL (2002). Secretaria de Informação e documentação. Subsecretaria de Informações. Legislação Republicana Brasileira. Brasília. 1 CD-ROM.

BRASIL (1973b). Decreto 73.079, de 05/11/1973. In: SENADO FEDERAL (2002). Secretaria de Informação e documentação. Subsecretaria de Informações. Legislação Republicana Brasileira. Brasília. 1 CD-ROM.

BRASIL (1984a). Decreto 89.311 de 23/01/1984. In: SENADO FEDERAL (2002). Secretaria de Informação e documentação. Subsecretaria de Informações. Legislação Republicana Brasileira. Brasília. 1 CD-ROM.

BRASIL (1984b). Decreto 89.758, de 06/06/1984. In: SENADO FEDERAL (2002). Secretaria de Informação e documentação. Subsecretaria de Informações. Legislação Republicana Brasileira. Brasília. 1 CD-ROM.

BRASIL. (1985) Lei 7.423, de 17/12/1985. In: SENADO FEDERAL (2002). Secretaria de Informação e documentação. Subsecretaria de Informações. Legislação Republicana Brasileira. Brasília. 1 CD-ROM.

BRASIL. Constituição (1937). Constituição dos Estados Unidos do Brasil, de 10/11/1937. In: BRASIL (1981). Constituições do Brasil. 5 ed., São Paulo: Atlas.

BRASIL. Constituição (1967). Constituição da República Federativa do Brasil, de 24/01/1967. (Redação final, atualizada até 04/10/1988). In: BRASIL (1981). Constituições do Brasil. 5 ed., São Paulo: Atlas.

CONSELHO FEDERAL DE EDUCAÇÃO (1962). Parecer 58, de 1962. In: CARVALHO, Guido Ivan de. (1975) Ensino Superior: legislação e jurisprudência. São Paulo: Revista dos Tribunais, v. 3, p. 50-63.

CONSELHO FEDERAL DE EDUCAÇÃO (1964). Parecer 166/64, de 02/07/1964. Documenta. Rio de Janeiro, n. 28, ago.

CONSELHO FEDERAL DE EDUCAÇÃO (1969) Parecer 970, de 05/12/1969. In: CARVALHO, Guido Ivan de (1975). Ensino Superior: legislação e jurisprudência. São Paulo: Revista dos Tribunais, v. 4. p. 376-378.

CONSELHO FEDERAL DE EDUCAÇÃO (1970) Parecer 881, de 12/12/1970. In: CARVALHO, Guido Ivan de (1975). Ensino Superior: legislação e jurisprudência. São Paulo: Revista dos Tribunais, v. 4. p. 484-487.

CONSELHO FEDERAL DE EDUCAÇÃO (1972). Parecer 436, de 08/05/1972. In: CARVALHO, Guido Ivan de (1975). Ensino Superior: legislação e jurisprudência. São Paulo: Revista dos Tribunais, v. 4, p. 84-89.

CUNHA, Luiz Antônio (1988). A Universidade reformanda: o golpe de 1964 e a modernização do ensino superior. Rio de Janeiro: Francisco Alves.

FERREIRA, Aurélio Buarque de Holanda (1999). Dicionário Aurélio eletrônico. Século XXI. Versão 3.0. 
GOMES, Joaquim Barbosa (2003). O Debate constitucional sobre as ações afirmativas. In: SANTOS, Renato Emerson dos e LOBATO, Fátima (orgs). Ações afirmativas: políticas públicas contra as desigualdades raciais. Rio de Janeiro: DP\&A.

HAIDAR, Maria de Lourdes Mariotto (1972). O Ensino secundário no império brasileiro. São Paulo: Grijalbo: Editora da Universidade de São Paulo.

HOUAISS, Antônio; VILLAR, Mauro de Salles; FRANCO, Francisco Manoel de Mello (2001). Dicionário Houaiss da língua portuguesa. Rio de Janeiro: Objetiva.

LIMA, Helena Ibiapina; FRANÇA, Flávio Antonio de Souza (2002). O acesso ao ensino superior no Brasil: resgatando a história do vestibular (1925-1961). Educação Brasileira. Brasília, v. 24, n. 48 e 49, p. 125-150, jan./dez.

OLIVEIRA, Carlos Alberto Serpa de (1985). A Comissão Nacional de Vestibular Unificado (CONVESU): origens e papel normativo. Educação e Seleção, São Paulo, n. 11, p. 13-19, jan./jun.

SOBRINO PÔRTO, Vicente (1970). Exame crítico da atual legislação sôbre o concurso vestibular. SIMPÓSIO SOBRE EXAMES VESTIBULARES, Salvador, 1970. Anais. Salvador:SBPC.

Notas:

${ }^{1}$ Lembro que, os egressos do ensino secundário eram frutos da Reforma Francisco Campos, sob a qual o ensino secundário estava dividido em ciclo fundamental e complementar.

${ }^{2}$ Não sei até que ponto a equivalência pode significar uma espécie de privilégio. Somente abordarei os que acredito atendem ao critério de privilégio.

${ }^{3}$ Curso de graduação com três anos de duração. Após a realização do curso na Seção de Formação, o aluno poderia completar seus estudos na Seção de Aperfeiçoamento com a duração de mais dois anos.

${ }^{4}$ A sigla significa United States Agency for International Development.

${ }^{5}$ A compilação do parecer a que tive acesso não revelava os nomes nem o número dos estudantes irregulares.

${ }^{6}$ Não encontrei na literatura consultada o significado da sigla SFVE.

Artigo recebido em: 05/06/2010

Aprovado em: 07/07/2010 